\title{
Developing an Integrated Land-Use/Transportation Model for Small to Medium-Sized Cities: Case Study of Montgomery, Alabama
}

By

Michael J. Clay ${ }^{1} \quad$ claymic@auburn.edu Kimberly Mullins² mullks@auburn.edu

Nicole Woerner ${ }^{2}$

Kristen M. Andersen ${ }^{2}$

John E. Abraham ${ }^{3}$ davist4@auburn.edu anderkr@auburn.edu jabraham@ucalgary.ca J.D. Hunt ${ }^{3}$ jdhunt@ucalgary.ca

Words: 5,278

Tables and Figures: 8

Total word count: 7,278

\author{
${ }^{1}$ Assistant Professor, \\ Graduate Community Planning Program \\ 104 Dudley Hall \\ Auburn University, Alabama, 36849, USA \\ Ph. 334-844-8412 \\ Fax. 334-844-5419 \\ Corresponding Author \\ ${ }^{2}$ Research Assistants, \\ Graduate Community Planning Program \\ 104 Dudley Hall \\ Auburn University, Alabama, 36849, USA \\ ${ }^{3}$ Institute for Advanced Policy Research \\ University of Calgary \\ Calgary, Alberta, T2N 1N4, Canada
}




\section{INTRODUCTION}

Local and regional governments make decisions that affect their citizens' quality of life and the economic vitality of the area. Important issues such as housing supply, transportation infrastructure development, and land use planning are vital to the local economy and should be combined with environmental, energy, and fiscal considerations to produce positive, sustainable outcomes. In an effort to account for these various systems in the planning process, many agencies are turning to computer-driven scenario and policy forecasting tools that allow them to model impacts and outcomes of alternatives before making selections for implementation. Travel demand models have been a part of regional transportation infrastructure planning for decades. These models use information such as roadway and transit networks and population and employment data to calculate the future demand for transportation facilities. As our computational resources and understanding of the transportation system have grown, much effort has gone into updating and improving these models. One of the more recent improvements incorporates dynamic land use representations into transportation modeling. These more complete modeling systems have outperformed traditional travel demand models in head-to-head comparisons (1-2).

While these models have enjoyed a broad array of academic analysis (3-5) and some limited practical exercises, there are barriers to their broader adoption, chiefly a lack of professional staff and budgetary resources at the local/regional government level. These deficiencies pose a considerable challenge not only to model calibration, but more fundamentally to the acquisition of the myriad of data required to fully develop an integrated land use and transportation model. Currently, only large metropolitan regions - with populations over one million persons - and state departments of transportation are developing these models. A possible reason for this is that these regions are dealing with larger, and perhaps more complex urban systems and therefore have a greater need for these tools. While this is a very reasonable explanation, we believe that were the staff and budgetary barriers removed, more metropolitan regions would move toward developing integrated land use and transportation modeling tools. The purpose of this demonstration study was to develop an integrated model for a typical small to medium-sized metropolitan region as a "proof of concept." It is anticipated that the methods used in this study will be of interest to similarly-sized metropolitan regions that have not previously considered the development of such a model to be feasible for them. This project resulted from a partnership between the Montgomery (Alabama) Area Metropolitan Planning Organization (Montgomery MPO) and the Urban Modeling Lab at Auburn University.

The remainder of this paper will proceed as follows. First, background information will be presented about the metropolitan region selected for this study. Next, the model selection process and criteria will be described, followed by a brief explanation of the specific integrated model chosen for this study. This will be followed by a discussion of data development and model calibration work that has taken place thus far. Finally, recommendations will be provided for other cities/regions interested in following a similar process.

\section{CASE STUDY BACKGROUND}

The Montgomery Area MPO encompasses portions of three counties in central Alabama: Autauga, Elmore, and Montgomery. The study area's largest city, Montgomery (pop. 200,000), is located at the intersection of Interstates 65 and 85 and is bounded to the north by the Alabama River and the south by large floodplains and designated wetlands. Autauga and Elmore Counties 
are experiencing rapid growth as commuters take advantage of the relatively high levels of accessibility to Montgomery employment centers provided by interstate and state highway improvements. In 2000, the Montgomery metropolitan region had a population of roughly 300,000 and forecasts a population of roughly 410,000 in 2030.

The Montgomery Area MPO shares many characteristics with other small to medium sized metropolitan regions in the US, making it a suitable case study for this project. The agency's annual operating budget (approximately US \$400,000), number of full-time transportation planning staff (one), and metropolitan population are not atypical. The average household size (2.4 persons) and median household income (roughly US \$37,000) are also unexceptional. Economically, this region does not serve as a national port of entry and competes with the larger economies of Atlanta to the east, Birmingham to the north, and Mobile to the south for new jobs and households. Manufacturing makes up a significant portion of the local economy.

While in many ways Montgomery is a typical small US city, there are at least two local attributes that may not be representative of small cities nationwide. First, Montgomery is the capital of Alabama and possesses a comparatively large share of government employment. Second, the racial composition of the Montgomery region is typical of other southeast US metropolitan regions but is likely disparate from more general, national statistics. Nearly $40 \%$ of the region is Black/African American and roughly 50\% of the city of Montgomery is Black/African American. Other racial/ethnic minority populations are small ( $1 \%$ or less).

\section{MODEL SELECTION}

After initial meetings with MPO staff several criteria were created for evaluating the various integrated land use and transportation models currently available. These criteria focused on: 1) the credibility of the model in terms of believability of outputs and the validity of the processes that generate the model outputs; 2) usability, meaning level of geography, temporal detail, model runtime, expertise required, policy relevance, model's ability to be linked with the region's existing travel demand model, utilization of open source code, and the purchase/license price of the software; and finally, 3) feasibility, including the cost to implement in staff time and fiscal resources, extent of the model's data needs, and total time required to develop a running model.

Given these criteria, several models were considered for use in this project, including: UPlan, MEPLAN, TRANUS, UrbanSim, and PECAS. These models were selected as roughly representative of three families of integrated models. UPlan represented the less complex, GISbased models that are easier to implement in shorter amounts of time, due to significantly lower input data requirements. MEPLAN and TRANUS represented self-contained land use and transportation models, and UrbanSim and PECAS represented land use models that integrate with the region's existing travel model. After careful analysis of the requirements and abilities of each of the models, and the needs of the sponsoring MPO, the pool was narrowed to UrbanSim (6) and PECAS (7) - microeconomics-based land use models that were designed to integrate with an existing travel demand model. Each represents floorspace developers explicitly and microsimulates development at the parcel or 50 meter gridcell level.

Both UrbanSim and PECAS have a conceptually believable and behaviorally valid method for representing location choice for employment and households and land or floorspace 
development. In addition to location choice and land development, PECAS also utilizes a square make-use table that includes households (derived from a full social accounting matrix-SAM) to generate the demand for land, products, and services. This spatial accounting of economic activity enables the model to consider a broad array of urban economic policies in addition to the traditional land use regulatory policies and transportation infrastructure alternatives that can be considered in the UrbanSim model. This means that PECAS endogenously represents a larger share of the regulatory, demographic, and economic processes associated with urban development. Both of these models use discrete choice representations of location choice and floorspace construction. As a result of this analysis, the MPO selected PECAS as the integrated model that would be used in this project.

\section{SURVEY OF CURRENT USERS}

In the Spring of 2005, a phone survey was conducted of agencies that had developed, or were in the process of developing UrbanSim or PECAS models. The aim of this informal survey was to gather basic data on the costs of model development. Five questions were asked: 1) which model is the agency developing; 2) how much financial resources have been invested in the model development process; 3) how much staff time, measured in full-time employee equivalency (FTE), has been invested in the model development process; 4) what other models were considered prior to adopting the model currently being developed; and 5) how much time did it take, or did the agency estimate it would take, to produce a usable model. In most cases no other model was considered; the agencies were aware of the chosen model and decided to use it with little to no evaluation of it against other models. This is not surprising, as UrbanSim and PECAS represent what the agencies consider to be the state-of-the-art in integrated land use and transportation modeling practice.

The data obtained from this survey represent rough approximations rather than exact figures. Table 1 presents a reasonable picture of what these agencies have spent and committed

on model development. It can be seen from this table that the time and money spent varies by agency and corresponded to some extent with whether data and model calibration were done inhouse or outsourced to consultants. 
TABLE 1 Results from Survey of Current Integrated Model Users in the Early Stages of Developing an UrbanSim or PECAS Model

\begin{tabular}{|c|c|c|c|c|}
\hline & Time to Develop & Cost in Dollars & Cost in FTE & $\begin{array}{c}\text { Other Models } \\
\text { Considered }\end{array}$ \\
\hline $\begin{array}{l}\text { Wasatch Front } \\
\text { Regional Council }\end{array}$ & 3 years & $\$ 500,000$ to date & 3.5 & N/A \\
\hline $\begin{array}{l}\text { Puget Sound } \\
\text { Regional Council }\end{array}$ & 2.5 years & $\$ 300,000 /$ year & 1.0 & $\begin{array}{l}\text { Previously used } \\
\text { DRAM/EMPAL }\end{array}$ \\
\hline $\begin{array}{l}\text { Alamo Area } \\
\text { Council of } \\
\text { Governments }\end{array}$ & 3 years & $\$ 150,000 /$ year & 2.0 & $\begin{array}{l}\text { Topaz, MEPLAN, } \\
\text { TRANUS, } \\
\text { Transtep, } \\
\text { Previously using } \\
\text { DRAM/EMPAL }\end{array}$ \\
\hline $\begin{array}{l}\text { Houston-Galveston } \\
\text { Area Council }\end{array}$ & 3 years & $\begin{array}{l}\$ 200,000 / \text { year to } \\
\text { develop, an } \\
\text { additional } \\
\$ 400,000 \text { for } \\
\text { subsequent updates }\end{array}$ & $\begin{array}{l}3 \text { during model } \\
\text { development, } 4 \text { for } \\
\text { subsequent updates }\end{array}$ & $\begin{array}{l}\text { Previously used } \\
\text { DRAM/EMPAL }\end{array}$ \\
\hline $\begin{array}{l}\text { Oahu Metropolitan } \\
\text { Planning } \\
\text { Organization }\end{array}$ & $\begin{array}{l}3 \text { years so far } \\
\text { (model completion } \\
\text { date is uncertain) }\end{array}$ & $\begin{array}{l}\$ 200,000 \text { total to } \\
\text { date }\end{array}$ & 0 & $\begin{array}{l}\text { UrbanSim was } \\
\text { recommended by } \\
\text { consulting firm }\end{array}$ \\
\hline $\begin{array}{l}\text { Southeast } \\
\text { Michigan Council } \\
\text { of Governments }\end{array}$ & 3 years & $\$ 500,000 /$ year & 6.0 & $\begin{array}{l}\text { Previously used } \\
\text { DRAM/EMPAL }\end{array}$ \\
\hline Oregon TLUMIP & $\begin{array}{l}8 \text { years total for the } \\
\text { TRANUS and } \\
\text { Gen. II models }\end{array}$ & $\$ 750,000 /$ year & 2.0 & $\begin{array}{l}\text { MEPLAN, } \\
\text { TRANUS, Delta, } \\
\text { Dortmund, others }\end{array}$ \\
\hline $\begin{array}{l}\text { Sacramento Area } \\
\text { Council of } \\
\text { Governments }\end{array}$ & 5 years & $\$ 240,000 /$ year & 0.3 & UrbanSim \\
\hline $\begin{array}{l}\text { Ohio Department } \\
\text { of Transportation }\end{array}$ & 3 years & $\$ 200,000 /$ year & .2 & N/A \\
\hline
\end{tabular}

\section{THE PECAS MODEL}

PECAS or its components have been applied in the development of state-wide transportation land-use modeling systems for the states of Ohio and Oregon, for the Sacramento region (7), the Baltimore MD region, and have been selected for use in a number of other locations. PECAS was designed to simulate spatial economic systems, and operates by clearing spatial submarkets for various goods, services and factors in a short-run equilibrium, with floorspace supply handled separately based on development probabilities. The model is composed of two separate modules: Space Development (SD) and Activity Allocation (AA) (see Figure 1). The SD module represents the actions of the developers in the study area by providing the supply of floorspace to be consumed by locators. On the demand side, the AA module represents how activities locate within the space provided by developers and how the activities interact with each other at a particular point in time. 


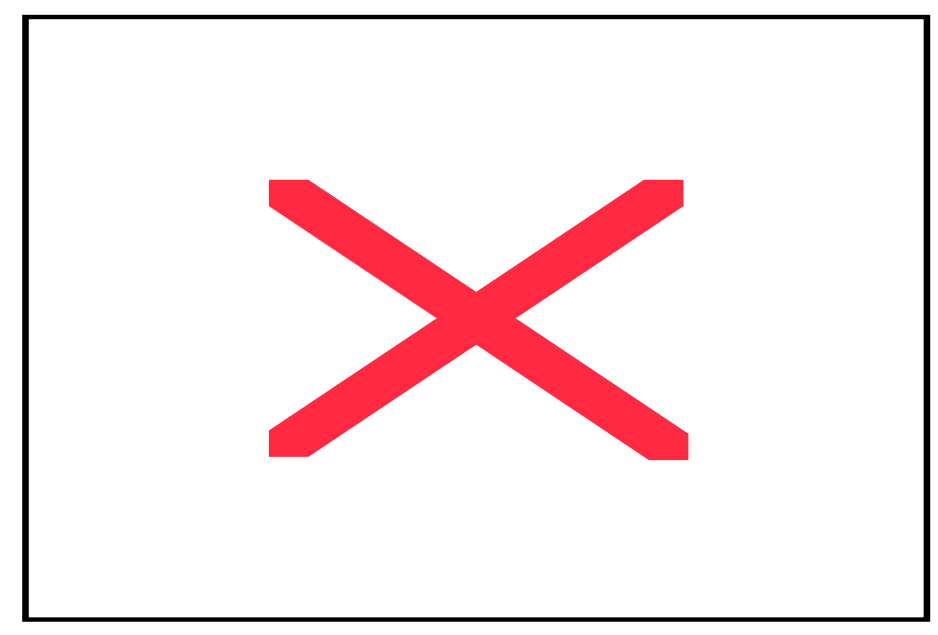

FIGURE 1 Interactions among modules simulating temporal dynamics. Source: Hunt and Abraham, 2003, p. 13

The PECAS model works through time in a series of discrete steps, allowing the AA module to run at each step and the SD module to consider the development possibilities from one point of time to the next. The AA module is based on the spatially disaggregated forms of extended "make" (production of commodities) and "use" (consumption of commodities) tables. In turn, the movement of commodities is the economic foundation of travel within the model. The make and use technical coefficients determine the rates at which activities produce and consume commodities in an elastic format and therefore represent the opportunities for substitution.

Initially, the business and government sectors of the economy are divided into industrial sector categories and then separated further based on the type of employment and associated space consumed. Furthermore, different household types are included in these categories and labor is treated as a commodity that is produced within these different households. Different types of floorspace (a non-transportable commodity) are included as commodities in the use table, while the quantity of floorspace available is a part of the AA module. Eventually, the exchange zones simulate markets where the aggregate supply meets the aggregate demand and the module then solves for the equilibrium solution, adjusting the exchange prices in the exchange locations until all markets clear.

The SD module is a microsimulation model of developer behavior. The module considers individual small units of land, which are called "parcels" in PECAS and can be based on legal parcels or can be grid cells. The parcels are small enough so that the diversity of land cover can be represented with a single type of building, a single building age (year built), and a single intensity of development (ratio of building space to land size) for each parcel. In urban models, parcel sizes are typically no more than one acre. (Large areas of homogeneous current coverage can be input as a single parcel, and the module will consider it as multiple smaller parcels, subdividing the parcel if and when development events are simulated on the land.)

Current rents for different space types are a zonal level input produced by the AA module. The SD module takes these rents, modifies them according to each parcel's specific conditions regarding micro-location (exposure along busy roads, age of structure, etc.) and compares them to a construction cost function (which considers specific parcel attributes such as 
demolition costs based on current building stock, and any fees or incentives due to zoning regulations), to determine an expected net profit from future rent revenue. Those space types and intensities that are permitted by zoning regulations and have a high net profit are more likely to occur on any given parcel. A random number generator is used to simulate specific development events on specific parcels.

By always comparing alternative uses (including "vacant" uses) with each other (and with the "no change" alternative) the cost of the land itself becomes irrelevant. Land is a sunk cost that applies to all alternatives equally and hence can be eliminated in the logit framework.

\section{MODEL DEVELOPMENT PLAN}

The Montgomery model will be completed in three one-year phases. The project officially began on October 1, 2006, and during the first year work has focused on two general tasks: model calibration and data development. The first-year goal was to produce an operational prototype model capable of demonstrating the integrated model's basic functions by simulating various land use and transport scenarios. Demonstration of this prototype will allow model developers to solicit feedback before beginning work on the more robust final model, which will be based on more complete data. Funding for the first year totaled US \$150,000 and a similar level of funding is expected for the two addition model development years.

Pending the successful evaluation of the project's first year and the procurement of second year funds, data development and model calibration improvements will remain on going but with a greater focus on increased input and involvement from local planning staff. Added to the second year tasks will be the creation of modeler/developer-level documentation for the PECAS model. It is anticipated that by the conclusion of year two a fully calibrated, integrated model will be produced.

In the project's third year, efforts will focus on development of a graphical user interface (GUI) and user-level documentation for the fully-functioning model. Cube Voyager will likely play a significant role in the GUI. Currently, operation and manipulation of the PECAS model is a fairly arduous process best performed by highly skilled modelers. Once the GUI has been created, however, local planning staff within the Montgomery MPO will be able to operate the final version of the model, included generating and testing policy alternatives. The GUI and documentation produced will be adaptable for use by other government planning organizations, which could further reduce the staff and budget required for such models.

\section{Agile Development}

An "Agile" iterative development approach is being undertaken (8). In iterative development, the focus is on creating software systems in stages, with each stage providing added value.

There are a number of Agile Development methodologies, but most are quite specific to software development in particular. For this project, the software already exists, but the approach of "small steps" had proven successful in the Sacramento PECAS Model (9). The principles of Agile Development provided a more formal approach to small step development than pursued in Sacramento, but the specifics needed to be adjusted to apply software development techniques to a computer modeling project where the software was already developed. 
The focus in iterative development is on improved working systems every "time box" or iteration. In this project, the iterations were chosen to correspond with the visits with or by the developers of PECAS. These visits were one to three months apart, so an improved functioning model was produced every one to three months. External deliverables were planned in year-long phases, so not every improved functioning model is a deliverable model, but the focus is on always having a working model that is, as much as possible, a "full" model (i.e. to strive for completeness first and to add detail later).

To focus the project on Agile Development from the beginning, the project was begun at a three-day "PECAS Workshop," where an initial working version of the AA module was completed in a group setting with other modelers working on models of other regions. Some of the data was made up based on hunches or simple web searches, and other aspects of the model were too simple to be very practically useful, but nonetheless a large part of the entire project was running within just a few days, and some calibration had begun. This model has been improved over several iterations since, and a working SD module is now integrated with the AA module.

One objective of Agile Development is to avoid project failures late in the project process. It has been characterized as a "fail early" approach, so that by the time a project approaches its final deadline all the major risks should have been addressed and only last minute improvements are being undertaken, all of which are either sure-to-succeed or optional. To this end, a list of needed and desired model features is kept for the Montgomery project. During each iteration, features are scored according to three dimensions: Risk, Value and Effort. A LowMedium-High scoring for each dimension has been used. The most important tasks are those corresponding to a feature with a high risk and high value. Low risk features can be added at the end of the modeling project. Low value features tend to be optional- they are not critical to the success of the modeling project. A focus, then, is on the tasks that have a high risk (high probability of causing the project to fail due to potential problems in the implementation, data quality, or procedure) and also a high value. The Effort ranking is for comparison with the Value ranking - high Value features with a low Effort should be included in the model; high Value features with a high Effort may not be affordable in the model depending on how the project, and its budget, progresses. Table 2 shows an example of a Risk, Value, Effort assessment of features early in the project.

Features are not the same as tasks. The Risk-Value-Effort assessment relates to features that can be added to the model. As much as possible, the focus in Agile Development is on features. But there are tasks that need to be undertaken to support the addition of model features, and these tasks still need to be identified, but without detracting from the Agile philosophy of focusing on incrementally improving a working modeling system. Each feature is likely to require some work on many tasks. Tasks that have been identified for the first deliverable model include:

1. Develop roughly 360 land use analysis zones to match the 360 TAZs in the

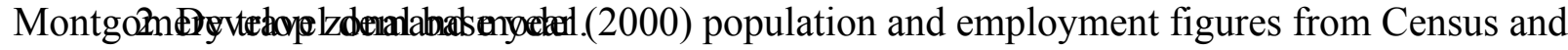
InfoUSA data.

3. Develop labor make and use rates, and residential floorspace use rates from Census PUMS (microsample) data.

4. Obtain region-wide travel conditions (skims) from network model for base year.

5. Convert economic data from a commercially available county-level input-output model (IMPLAN) to PECAS format. 
6. Collect floorspace rent data from recent residential sales and county assessor data.

7. Construct Activity Allocation system using existing open-source PECAS software. etc.).

8. Establish base case prototype future-year inputs (e.g., networks, zoning regulations,

9. Synthesize floorspace onto parcel data, with quantity of floorspace validated on population and employment data.

10. Calibrate to base year.

TABLE 2 An Example of a Risk-Value-Effort Assessment of Features Early in the Montgomery PECAS Project (Shaded Features Were Chosen for Subsequent Iterations)

\begin{tabular}{llll}
$\begin{array}{l}\text { ACTIVITY ALLOCATION } \\
\text { Feature }\end{array}$ & Risk & Value & Effort \\
\hline Zonal details & Low & High & Medium \\
Industry disaggregation & Low & High & Medium \\
Household disaggregation & Low & High & Medium \\
Commodity disaggregate goods/services/labor & Low & Medium & Medium \\
Commodity-specific transport costs & $?$ & $?$ & ? \\
Floorspace type disaggregation & Medium & High & Medium \\
Inertia term calibration & Medium & Medium & Medium \\
Import/Export Calibration & Low & Medium & Low \\
Short-term floorspace supply calibration (use as & Low & Medium & High \\
price targets the rent inputs from SD) & Medium & High & Medium \\
Link outputs to TDM & Medium & High & Medium \\
Link TDM skims to AA & & &
\end{tabular}

\section{SPACE DEVELOPMENT}

\begin{tabular}{llll} 
Feature & Risk & Value & Effort \\
\hline $\begin{array}{l}\text { Parcel database prep/integration } \\
\text { - Including pseudo parcels }\end{array}$ & Medium & High & High \\
- Categorizing existing space & & & \\
- Categorizing existing zoning regulations & & & \\
Construction cost functions & Low & Medium & Low \\
Construction history/development permits & High & Medium & High \\
\hline $\begin{array}{l}\text { Initial calibration of dispersion/constants } \\
\text { SD Overrides }\end{array}$ & Medium & High & Medium \\
Price (rent) inputs for calibration & $?$ & $?$ & $?$ \\
\hline
\end{tabular}

\section{COMBINED SYSTEM}

\begin{tabular}{llll}
\hline Time series calibration & Medium & High & High \\
Scripts and year-by-year data transfer & Low & High & High
\end{tabular}




\section{DATA DEVELOPMENT}

The amount of information required for successful operation of an integrated model is extensive. Tables 3 and 4 summarize the input data required for each of the PECAS submodules.

To obtain this information, researchers collaborated with local government staff throughout the study area, as well as local real estate and construction professionals. These efforts generally yielded good quality data at the zonal level but difficulties arose at the parcel level, especially for parcels in rural areas. Aerial photography was used to help identify attributes of rural parcels. Triangulation of multiple data sources was used whenever possible to increase the quality/accuracy of input data. Numerous discrepancies were found between data obtained from different sources. Local expertise was used to resolve these differences and identify the "most likely" case in ambiguous situations. Once cleaned, data was integrated from disparate sources into a single, standardized spreadsheet/data base for input into the PECAS model. The Activity Allocation sub-module uses a single, custom-formatted Excel spreadsheet containing a series of interconnected/linked worksheets from which input data are drawn and to which output data are reported. The Space Development sub-module uses Access databases to house its inputs and report outputs. The separate formats are an artifact of the differences in the number of records needed (e.g. 360 zones in AA vs. 134,658 parcels in SD).

Often, the zonal structure used in the land use portion of integrated models consists of agglomerations of the region's TAZs (see 1 and 2 for examples). Since the number of TAZs in this study area is relatively small (360), modelers used the same zonal structure for the land use and travel demand models, in order to simplify the exchange of data between the two models (i.e. the $360 \mathrm{TAZs}$ correspond geographically to the 360 land use analysis zones). This also simplified data gathering, as much of the data provided by the MPO had been collected at the TAZ level.

Resolving spatial mismatches between data sets proved to be a time-consuming task. As is often the case, TAZ boundaries did not relate to census tract or block group boundaries and none of the spatial data were aligned with parcel boundaries. In retrospect, realigning the TAZ boundaries likely would have been easier than making the numerous "judgment calls" that the inconsistent boundaries required.

Each jurisdiction in the study area uses a unique set of zoning categories. Zoning layers obtained from city and county officials were adjusted to create a single layer with a uniform set of zoning categories applied to the entire region. Land use categories were manipulated in a similar way, and all parcel sizes were converted into square feet. Once all land parcel attributes had been standardized, students collected parcel data from all three counties into a single spreadsheet. Zoning designations, land use, municipal boundaries, and building information were attached to each parcel. Parcels were designated built or vacant, and on built parcels the type of use, area, and rent value of the structure was noted in the database, and building footprints assigned to the appropriate parcel. Vacant, non-built parcels were categorized as buildable and non-buildable. A parcel was categorized as non-buildable if it had attributes such as federallyprotected waterways, wetlands, and forests, excessive slopes, local and state parks, and cemeteries. 
TABLE 3 Input Data Requirements for Activity Allocation Sub-module

\begin{tabular}{|l|l|l|l|}
\hline \multicolumn{1}{|c|}{ Required Data } & Level of Geography & \multicolumn{1}{|c|}{ Categories } & \multicolumn{1}{|c|}{ Data Source } \\
\hline Land Use Analysis Zones & $\begin{array}{l}\text { Variable-this project } \\
\text { used the existing Traffic } \\
\text { Analysis Zones }\end{array}$ & N/A & $\begin{array}{l}\text { MPO's existing } \\
\text { travel demand } \\
\text { model }\end{array}$ \\
\hline $\begin{array}{l}\text { Local Economic } \\
\text { Interactions }\end{array}$ & Full MPO Study Area & $\begin{array}{l}\text { Variable-this project uses } \\
7 \text { categories of employment } \\
\text { and 3 categories of } \\
\text { households }\end{array}$ & $\begin{array}{l}\text { IMPLAN county } \\
\text { level input/output } \\
\text { models aggregated } \\
\text { to the full MPO } \\
\text { study area }\end{array}$ \\
\hline $\begin{array}{l}\text { Base-year location of } \\
\text { households by type }\end{array}$ & $\begin{array}{l}\text { Traffic/Land Use } \\
\text { Analysis Zones }\end{array}$ & $\begin{array}{l}\text { Variable-this project uses } \\
\text { Low, medium, and high } \\
\text { income }\end{array}$ & US Census \\
\hline $\begin{array}{l}\text { Base-year location of } \\
\text { employment by type }\end{array}$ & $\begin{array}{l}\text { Traffic/Land Use } \\
\text { Analysis Zones } \\
\text { Government/military, } \\
\text { Industry/manufacturing, } \\
\text { Office/professional, Natural } \\
\text { resource based/agriculture, } \\
\text { Medical, Education, and } \\
\text { Retail }\end{array}$ & InfoUSA data \\
\hline $\begin{array}{l}\text { Base-year location of } \\
\text { housing by type }\end{array}$ & $\begin{array}{l}\text { Traffic/Land -this project uses } \\
\text { Analysis Zones } \\
\text { Single family detached, } \\
\text { Mobile Home }\end{array}$ & US Census \\
\hline Generalized accessibility & $\begin{array}{l}\text { Traffic/Land Use } \\
\text { Analysis Zones }\end{array}$ & N/A & $\begin{array}{l}\text { MPO's existing } \\
\text { travel demand } \\
\text { model }\end{array}$ \\
\hline
\end{tabular}

Base year population and employment data was developed by integrating information from various sources. Summary files, Public-Use Microdata Samples (PUMS) data, and Census Transportation Planning Package (CTPP) data from the 2000 Census supplemented information from the private sector, such as employment data from InfoUSA and county level input-output tables from IMPLAN. PUMS housing data was used together with the aggregated input-output tables to develop labor make and use rates for each county in the study area. This data was analyzed, together with land cover data, zoning regulation data, and appropriate housing categories. Cross-tabulations of the microsample data were used to determine the relationships between industry and occupation, between household categories and occupation, and between household categories and housing categories.

In order to microsimulate floorspace development and to validate the base year prices obtained from the model's floorspace bidding process, present lease values for the various types of floorspace represented in the model needed to be acquired. Locating information on floorspace usage and price proved challenging. No adequate list was found containing floorspace lease rates by type by size (measured in square feet) for the study area. Census housing data, combined with data obtained from leasing agents and real estate professionals provided a partial non-random sample of floorspace quantity and price throughout the region. Build construction costs - by type by square foot - were obtained from local developers, who met with the modeling team to ensure the representation of their industry was roughly correct, with locally valid cost data. Site improvements and site specific issues such as soil and slope were separated out in the construction cost estimates and are considered independently in the model. 
TABLE 4 Input Data Requirements for Space Development Sub-module

\begin{tabular}{|l|l|l|l|}
\hline \multicolumn{1}{|c|}{ Required Data } & \multicolumn{1}{c|}{ Level of Geography } & \multicolumn{1}{c|}{ Categories } & \multicolumn{1}{c|}{ Data Source } \\
\hline $\begin{array}{l}\text { Spatial representation of } \\
\text { legal parcels (alternatively } \\
50 \text { meter grid cells could } \\
\text { be used) }\end{array}$ & Legal parcels & $\begin{array}{l}\text { Variable-this project uses } \\
14 \text { Built (zoning/land use } \\
\text { categories) and 2 vacant } \\
\text { (buildable and non- } \\
\text { buildable) }\end{array}$ & $\begin{array}{l}\text { County Assessor; Aerial } \\
\text { photography; Floodplain } \\
\text { insurance maps }\end{array}$ \\
\hline Zoning & Legal parcels & $\begin{array}{l}\text { Variable-this project uses } \\
\text { a simplified 14 category } \\
\text { zoning scheme }\end{array}$ & $\begin{array}{l}\text { Local governments land } \\
\text { use general plans }\end{array}$ \\
\hline $\begin{array}{l}\text { Amount and scale of } \\
\text { historic development }\end{array}$ & Legal parcels & $\begin{array}{l}\text { Residential and non- } \\
\text { residential }\end{array}$ & $\begin{array}{l}\text { Archival building permit } \\
\text { data obtained from local } \\
\text { building departments }\end{array}$ \\
\hline $\begin{array}{l}\text { Costs of developing } \\
\text { floorspace by type }\end{array}$ & Full MPO Study Area & $\begin{array}{l}\text { Variable-this project uses } \\
3 \text { categories of residential } \\
\text { and 9 categories of non- } \\
\text { residential }\end{array}$ & Local developers \\
\hline $\begin{array}{l}\text { Market value of floorspace } \\
\text { by type }\end{array}$ & $\begin{array}{l}\text { Full MPO Study Area } \\
\text { broken into real estate } \\
\text { submarkets }\end{array}$ & $\begin{array}{l}\text { Variable-this project uses } \\
3 \text { categories of residential } \\
\text { and 9 categories of non- } \\
\text { residential }\end{array}$ & $\begin{array}{l}\text { Local real estate } \\
\text { professionals and multiple } \\
\text { listing service (MLS) }\end{array}$ \\
\hline
\end{tabular}

A completely accurate input database is impossible to assemble, and not necessary for successful operation of an integrated modeling system. Data development is an ongoing process. As data improvement milestones are reached, model calibration is updated accordingly.

\section{MODEL INTEGRATION}

Modelers chose to use the Cube Voyager software package to integrate PECAS with the MPO's travel demand model, for several reasons. First, the case study MPO already uses travel demand modeling software developed and supported by Citilabs (the proprietors of Cube). This software is supported both technically and fiscally by the Alabama Department of Transportation and is familiar to MPO staff. Second, Cube Voyager easily integrates external software and submodels into its normal operation, greatly simplifying the integration process. Third, Cube's self-contained output display capabilities and its ability to readily link outputs to GIS visualization tools is more efficient than earlier models such as MEPLAN and TRANUS, which display their outputs in spreadsheet format only, and converting these outputs into graphic display can be a tedious process. For example, obtaining VMT outputs from MEPLAN requires several steps, including data format conversions and spreadsheet calculations.

Prior to this project, the case study MPO's travel demand model only contained two networks: a 2000 base year network, and a 2030 network - the horizon year for this project. The travel model runs every year, in conjunction with PECAS. Each year, a new land use pattern is fed from PECAS to the travel demand model and a new set of zonal, generalized accessibilities is passed from the travel model to PECAS. In order for this process to work properly, the travel model needed intermediate networks that represent the planned and future transportation infrastructure projects contained in the MPO's transportation improvement program (TIP) and long range development plan (LRDP). These networks can be developed by either adding to the base year network or subtracting projects from the out year network. For this project, the out 
year network was reduced year-by-year back towards the base year in a manner congruent with the MPO's planning documents.

The travel demand model originally contained only three of the four traditional steps (i.e. trip generation, trip distribution, and traffic assignment). Though Montgomery has a revived and reasonably extensive local bus service, the mode choice step was not present in the model. As part of this project, a logit-choice mode split model was developed for the MPO. In addition to making the integrated modeling system more policy relevant for transit, this improvement had the added benefit of allowing the use of mode choice log sums as a measure of generalized, zonal accessibility (early on in the project time and distance skims were used from the traffic assignment step).

\section{CONCLUSIONS AND RECOMMENDATIONS}

The goal of this project was to develop a functioning integrated economic, land use, and transportation model for a medium-sized metropolitan region. Such a model can serve as a prototype for other small to medium sized MPOs across the country planning their own model development effort. The Montgomery area shares many similar characteristics with other small MPOs, making the region a suitable case study.

The PECAS model was chosen for this project because it can simulate a larger number of policy alternatives and model economic changes more explicitly than its competitors. Thus far, the "proof of concept" presented here has demonstrated that PECAS can be successfully adapted to the needs of a smaller region, despite the model's complex structure and considerable data requirements.

This project adopted an "Agile" incremental development method, with annual deliverables but much more frequent internal model improvement iterations. In this way, a working model has existed since the early stages of the project, though data collection efforts are ongoing.

Currently, the Montgomery project is approaching the end of its first year of model development. The project has achieved the objectives of the initial phase: to establish the model's framework, and produce an operational prototype model capable of demonstrating the integrated model's basic functions by simulating various land use and transport scenarios. Demonstration of this prototype to the Montgomery MPO will allow project leaders to solicit feedback before beginning work on a more robust final model. Developers will check the model results against local knowledge of existing and future conditions, and request input on how the model can be made more useful to local planners.

Several recommendations emerged from our experience with the Montgomery project, which we believe will minimize the barriers associated with the adoption of integrated models in smaller regions. For this project, initial funds were provided by the MPO via locally available Federal Transit Administration (FTA) and Federal Highway Administration funds with the intent to shift the funding source to FHWA State Planning and Research funds in subsequent project years. For agencies with access to these funding sources this seems a feasible revenue strategy as these moneys can readily be applied towards modeling activities. By partnering with an outreach-focused university, local and regional governments can benefit from university staff, expertise, and student labor. As in our case study, this type of partnership can make a model development program of this type feasible for smaller metropolitan regions. 
Though data collection and maintenance capabilities in smaller metropolitan regions may be less sophisticated than their larger counterparts, this issue should not prevent smaller MPOs from seeking to implement an integrated model development project. In the Montgomery case study, information from local governments was supplemented by a variety of public and private data sources - at a reasonable cost (in time and money) - to produce datasets sufficient to begin calibration of a PECAS model.

Selecting the proper scale at which to development an integrated model is keenly important. Integrated models should be implemented at the metropolitan/regional level. Smaller geographies contain too high a share of external economic interactions and external vehicle trips. Though the economic system simulated by the model will necessarily include exchanges made outside the region, the vast majority of economic activity being modeled should take place within the modeled system. Similarly, regional models must be large enough to encompass the commuting shed of a metropolitan area, minimizing the number of transportation-related interactions outside the system. In the US case, it is common that the federally mandated travel demand model operate at the regional level. Developing the economic/land use model at this same level of geography simplifies the necessary interactions between these models. MPOs are well-suited to sponsor model development projects, since these organizations have a region-wide leadership structure already in place.

For an integrated modeling project to be successful it is vital to receive and maintain the support of local government officials. Local "buy-in" promotes two critical objectives. First, it ensures model developers have access to the best locally available data, and second, governments fully engaged in the model development process will be more likely to participate in planning and/or policy changes suggested by the outcomes of alternative scenario tests performed with the final model.

Montgomery's PECAS model is an example of a successful integrated economic, land use, and transportation model developed for a small to medium sized region. Historically, such projects had been undertaken primarily by the country's largest metropolitan regions. Yet challenges associated with population growth, environmental degradation, and traffic congestion are not limited to large metropolitan areas, and regions of all sizes can benefit from access to this dynamic, policy analysis and scenario evaluation tool. 


\section{REFERENCES}

1. Hunt, J. D., R. A. Johnston, J. E. Abraham, C. J. Rodier, G. R. Garry, S. H. Putman, and T. de la Barra. Comparisons from Sacramento Model Test Bed. In Transportation Research Record: Journal of the Transportation Research Board, No. 1780, TRB, National Research Council, Washington, D.C., 2001, pp. 53-63.

2. Condor, S. and K. Lawton. Alternative Futures for Transportation and Land Use Integrated Models Contrasted with "Trend-Delphi” Methods: The Portland Metro Results. Presented at the 81st Annual Meeting of the Transportation Research Board, Washington, D.C., 2002.

3. Rodier, C., J. E. Abraham, R. A. Johnston and J. D. Hunt. Anatomy of Induced Travel Using an Integrated Land Use and Transportation Model in the Sacramento Region. Presented at the 80th Annual Meeting of the Transportation Research Board, Washington, D.C., 2001.

4. Clay, M. J. and R. A. Johnston. Univariate Uncertainty Analysis of a Fully Integrated Land Use and Transportation Model: MEPLAN. Transportation Planning and Technology, Vol. 28, No. 3, 2005, pp. 149-165.

5. Clay, M. J. and R. A. Johnston. Multivariate Uncertainty Analysis of a Fully Integrated Land Use and Transportation Model: MEPLAN. Transportation Research D:

Environment and Travel, Vol. 11, No. 3, 2006, pp. 191-203.

6. Waddell, P. UrbanSim: modeling urban development for land use, transportation and environmental planning. Journal of the American Planning Association, Vol. 68, No. 3, pp. 297-314.

7. Hunt, J. D. and J. E. Abraham. Design and Application of the PECAS Land Use Modelling System. Presented at the 8th Computers in Urban Planning and Urban Management Conference, Sendai, Japan, 2003.

8. Larman, C. Agile and Iterative Development: A Manager's Guide. Addison-Wesley Professional, Boston, 2004.

9. Abraham, J. E., G. R. Garry, A. T. Brownlee and J. D. Hunt. Land Use Transport Modelling in Sacramento: Small Steps Towards a Grand Design. Presented at the 8th International Conference on Computers in Urban Planning and Urban Management, Sendai, Japan, 2003. 